\title{
Causes and patterns of readmissions in patients with common comorbidities: retrospective cohort study
}

\section{(@) $(1)$ OPEN ACCESS}

\author{
Jacques Donzé research associate ${ }^{123}$, Stuart Lipsitz professor ${ }^{12}$, David W Bates professor ${ }^{124}$, \\ Jeffrey L Schnipper associate professor ${ }^{125}$
}

'Division of General Internal Medicine and Primary Care, Brigham and Women's Hospital, Boston, MA 02120, USA; ${ }^{2} \mathrm{Harvard}$ Medical School, Boston, MA 02115, USA; ${ }^{3}$ Division of General Internal Medicine, Bern University Hospital, 3010 Bern, Switzerland; ${ }^{4}$ Harvard School of Public Health, Boston, MA 02115, USA; ${ }^{5}$ BWH Hospitalist Service, Brigham and Women's Hospital, Boston, MA 02115, USA

\begin{abstract}
Objective To evaluate the primary diagnoses and patterns of 30 day readmissions and potentially avoidable readmissions in medical patients with each of the most common comorbidities.

Design Retrospective cohort study.

Setting Academic tertiary medical centre in Boston, 2009-10.

Participants 10731 consecutive adult discharges from a medical department.

Main outcome measures Primary readmission diagnoses of readmissions within 30 days of discharge and potentially avoidable 30 day readmissions to the index hospital or two other hospitals in its network.

Results Among 10731 discharges, 2398 (22.3\%) were followed by a 30 day readmission, of which $858(8.0 \%)$ were identified as potentially avoidable. Overall, infection, neoplasm, heart failure, gastrointestinal disorder, and liver disorder were the most frequent primary diagnoses of potentially avoidable readmissions. Almost all of the top five diagnoses of potentially avoidable readmissions for each comorbidity were possible direct or indirect complications of that comorbidity. In patients with a comorbidity of heart failure, diabetes, ischemic heart disease, atrial fibrillation, or chronic kidney disease, the most common diagnosis of
\end{abstract}

potentially avoidable readmission was acute heart failure. Patients with neoplasm, heart failure, and chronic kidney disease had a higher risk of potentially avoidable readmissions than did those without those comorbidities.

Conclusions The five most common primary diagnoses of potentially avoidable readmissions were usually possible complications of an underlying comorbidity. Post-discharge care should focus attention not just on the primary index admission diagnosis but also on the comorbidities patients have.

\section{Introduction}

Preventable readmissions to hospital are frequent, costly, and demanding on healthcare resources; they also represent threats to patients' safety such as preventable adverse drug events, healthcare associated infections, procedural complications, and avoidable exacerbations in disease states or functional declines. The recent focus on readmissions in some countries, including the United States, Germany, Switzerland, and England, driven in part by their effects on costs, thus underlies a much more global concern about patients' safety.

Hospital readmission represents a multifaceted problem that still needs to be better understood. Evidence shows that

Correspondence to: J Donzé donze.author@gmail.com

Extra material supplied by the author (see http://www.bmj.com/content/347/bmj.f7171?tab=related\#webextra)

Video on bmj.com (see also http://bmj.com/video)

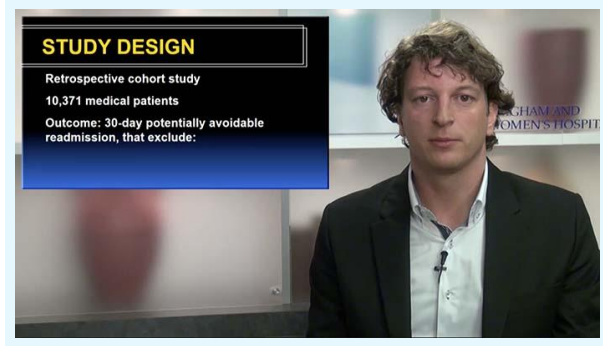


readmission diagnoses usually differ from the specific acute diagnosis responsible for the index hospital admission. ${ }^{12}$ On the other hand, higher comorbidity has been shown to be associated with an increased risk of readmission. ${ }^{3-5}$ Also, in a recent study, most of the 30 day readmissions after pneumonia were found to be comorbidity related. ${ }^{6}$ Thus, the role of comorbidities in causing readmissions is complex, but relatively few studies have looked at this. The subject will take on greater importance as a growing percentage of the world's population becomes older and the incidence of comorbidities rises.

A better understanding of the causes and patterns of readmissions in patients with common comorbidities may lead to more targeted and successful interventions, and these strategies may differ by condition. In addition, few data are available regarding to what extent the causes and patterns of all cause readmissions differ from the readmissions that are avoidable and thus actionable. We hypothesized that patients' comorbidities have an important role in the primary diagnosis of 30 day potentially avoidable readmission and that preventability of readmissions may vary among patients with different comorbidities. Therefore, our aim was to evaluate the primary diagnoses and patterns of 30 day readmissions and potentially avoidable readmissions according to the most common comorbidities in medical patients.

\section{Methods}

\section{Study design and population}

We included all consecutive discharges of adult patients from any medical service of the Brigham and Women's Hospital between July 12009 and June 30 2010. We included only discharges following a length of stay of more than 24 hours to avoid inclusion of stays for observation. Brigham and Women's Hospital is a 750 bed academic medical center in Boston, Massachusetts, with the following medical services: general medicine, cardiology, oncology, bone marrow transplant, endocrinology, gastroenterology, hematology, infectious diseases, rheumatology, and nephrology. Exclusion criteria were death before discharge, transfer to another acute healthcare facility, and discharge against medical advice.

\section{Study outcome}

The outcome of the study was any readmission within 30 days of discharge to any service of three hospitals within the Partners network in Boston, including Brigham and Women's Hospital, Massachusetts General Hospital (a 1000 bed tertiary care hospital), and Faulkner Hospital (a 150 bed community hospital closely affiliated with Brigham and Women's Hospital). More than $80 \%$ of all readmissions after an index medical admission to Brigham and Women's Hospital are captured in this network. ${ }^{78}$ We used a validated algorithm (SQLape) to identify among these readmissions the ones that were deemed potentially avoidable. ${ }^{910}$ This algorithm uses diagnostic and procedure codes of both index admission and readmission to differentiate potentially avoidable readmissions from unavoidable readmissions. More precisely, it excludes as unavoidable foreseen readmissions such as readmissions for transplantation, labor and delivery, chemotherapy or radiotherapy, and other specific surgical procedures. Follow-up and rehabilitation treatments are also considered unavoidable. Readmissions for a disease in a new system (for example, circulatory, respiratory, digestive, hepatic, nervous, blood) unknown to be affected during the preceding stay are also considered unavoidable. Also, readmissions due to some specific diseases deemed difficult to cure (such as multiple sclerosis and idiopathic thrombocytopenia) are considered unavoidable. Conversely, complications of treatment (for example, deep vein thrombosis, catheter associated urinary tract infection, drug induced disorders) are considered potentially avoidable, as are readmissions for conditions related to those present during the index admission (web appendix). The sensitivity and specificity of the screening algorithm both reached $96 \%$ when compared with medical chart review (using the same criteria) in a random sample of admission-readmission pairs. ${ }^{11}$ To exclude the possibility that administrative data contained incomplete information on the elective status of a readmission, nine senior medical residents excluded any readmissions deemed to be planned on the basis of the discharge summaries of both the index admission and readmission. These residents received one hour of training in how to perform this task, including review of several standardized cases.

\section{Comorbidities}

We retrieved the most frequent comorbidities by using the following ICD-9-CM (international classification of diseases, 9th edition, clinical modification) codes from the index admission: diabetes mellitus (249.00-250.99), congestive heart failure (428.x, 425.4-425.9, 402.01, 402.11, and 398.91), ischemic cardiac disease (410.00-414.99), atrial flutter/fibrillation (427.30-427.32), chronic obstructive pulmonary disease $(491.00-492.99,493.2$, and 496), chronic kidney disease (585.00-586.99), and neoplasm (140.00-239.99).

\section{Primary readmission diagnoses}

We then identified the 13 most frequent primary diagnoses that occurred in the entire cohort, both for all readmissions and for potentially avoidable readmissions. The following diagnoses were retained using Medicare Severity-Diagnosis Related Groups (MS-DRG) codes from the readmission: heart failure (291-293, 189), chronic obstructive pulmonary disease (190-192), cardiac ischemic disease (231-236, 246-251, 280-285), arrhythmia (308-310), cerebrovascular diseases (061-072), adverse drug events (917-923), renal failure (682-685), nutritional and metabolic disorders (640-641), venous thromboembolism (175-176, 294-295), liver disorders (405-434, 438-446), gastrointestinal disorders (391-392, 377-384), infectious diseases (075-076, 094-099, 121-122, 177-179, 193-195, 371-373, 485-489, 548-550, 689-690, 757-759, 853-863, 865-872), and neoplasm (054-055, 146-148, 180-182, 374-376, 435-437, 582-583, 597-599, 656-658, 686-688, 715-724, 736-741, 754-756, 846-849). We defined primary diagnoses for the index admissions in the same way. We chose MS-DRG codes for this purpose because they more closely correlate with the reason for the hospital admission than do ICD-9 CM codes.

\section{Statistical analysis}

We present patients' baseline characteristics as proportions, means with standard deviations, or medians with interquartile ranges as appropriate. The unit of analysis was any patient's index discharge from a medical service. To evaluate the importance of each comorbidity on the causes of readmissions, we identified the proportion of the five most common primary readmission diagnoses for each comorbidity for both all cause 30 day readmissions and potentially avoidable 30 day readmissions.

To further assess whether the primary readmission diagnosis was related to the primary diagnosis at index admission or to a comorbidity, we examined patients readmitted for a diagnosis 
closely related to a comorbidity (for example, readmission for acute heart failure exacerbation in a patient with a comorbidity of chronic heart failure) and then determined the proportion for whom that was also the primary diagnosis of the index admission (that is, whether or not acute heart failure was also the primary admission diagnosis for the index admission).

Next, to evaluate whether patients with a specific comorbidity were at higher risk of potentially avoidable readmission (versus no readmission), we calculated the crude and adjusted relative risk with $95 \%$ confidence interval of avoidable readmission between patients with versus without each comorbidity. We then used multivariable logistic regression with all comorbidities in the model, adjusted for the following potential confounders of potentially avoidable readmission: length of stay of index admission, mode of admission (elective or not), number of admissions in the previous 12 months, number of procedures during the index admission, and hemoglobin and sodium concentrations at the time of discharge of the index admission. ${ }^{12}$ We used generalized estimating equations to account for clustering due to repeated admissions of the same patient. ${ }^{13}$

We also calculated the crude and adjusted relative risks (the adjusted relative risks were calculated as ratios of adjusted probabilities from the logistic regression models) to evaluate whether patients with each of the comorbidities had a higher proportion of readmissions deemed potentially avoidable (versus unavoidable) compared with those without each comorbidity. For these models, we used the same covariates as in the previous analyses.

We evaluated all tests as two sided at a 0.05 level of significance. We used SAS software, version 9.3 for analyses.

\section{Results}

A total of 12383 patients were discharged from the medical services of the Brigham and Women's Hospital during the study period (fig $1 \Downarrow$ ). After exclusion of deaths before discharge $(n=363)$, transfers to another acute healthcare facility $(n=1217)$, and discharges against medical advice $(n=72), 10731$ discharges remained for analysis. Of these, $22.3 \%(\mathrm{n}=2398)$ were followed by a 30 day readmission, of which 858 ( $8.0 \%$ of all admissions, $35.8 \%$ of readmissions) were identified as potentially avoidable.

Table $1 \Downarrow$ shows baseline characteristics. The mean age in the entire cohort was 61.0 (SD 16.7) years at inclusion, and about half were male. The mean number of selected comorbidities for each patient's discharge was 1.74 (SD 1.22).

\section{Primary diagnoses for all cause and potentially avoidable readmissions}

Overall, the most common primary diagnoses of 30 day readmissions in the entire cohort were neoplasm $(16.8 \% ; \mathrm{n}=402)$, infection $(10.9 \% ; \mathrm{n}=260)$, heart failure $(4.9 \% ; \mathrm{n}=116)$, liver disorders $(4.4 \% ; n=105)$, and gastrointestinal disorders $(3.6 \%$; $\mathrm{n}=86$ ) (table $2 \Downarrow$ ). After we restricted the analyses to the potentially avoidable readmissions only, the three most common primary readmission diagnoses were infection $(11.6 \%$; $n=99)$, neoplasm $(8.4 \% ; \mathrm{n}=72)$, and heart failure $(7.1 \%, \mathrm{n}=61)$ (table $3 \Downarrow)$. The most frequent avoidable readmission diagnoses of infection were pneumonia and respiratory infection $(30.7 \%$; $31 / 99)$, septicemia $(29.7 \% ; 30 / 99)$, and kidney or urinary tract infection $(20.8 \% ; 21 / 99)$.

\section{Primary diagnoses of potentially avoidable readmission by comorbidity}

Heart failure and infection were the two most common readmission diagnoses for patients with most of the chronic comorbidities, accounting together for $21.6 \%$ to $34.3 \%$ of all avoidable readmissions (table $3 \Downarrow$ ). Only the patients with neoplasm did not have heart failure as one of the five most common primary readmission diagnoses. Heart failure was, however, the single most common primary diagnosis of avoidable readmission in patients with five of the seven studied comorbidities: chronic heart failure, ischemic heart disease, atrial fibrillation, diabetes mellitus, and chronic kidney disease (and was essentially tied for the most common diagnosis in patients with chronic obstructive pulmonary disease). Of note, $92 \%(110 / 120)$ of the patients with ischemic heart disease, atrial fibrillation, diabetes, and kidney disease readmitted for heart failure had a known comorbidity of chronic heart failure during the index admission. Other frequent primary diagnoses of avoidable readmissions in patients with comorbidities were neoplasm, ischemic heart disease, arrhythmia, renal failure, liver disorders, and gastrointestinal disorders.

\section{Relation of potentially avoidable readmission diagnoses to comorbidities}

The top five primary diagnoses of potentially avoidable readmissions (table $3 \Downarrow$ ) were almost all known or at least possible complications of each comorbidity. For example, patients with neoplasm were most frequently readmitted for care of their neoplasm or potentially related complications such as infection (for example, from immunosuppressive chemotherapy), metabolic disorder (for example, from cancer related syndrome of inappropriate antidiuretic hormone or therapy induced dehydration), gastrointestinal disorder (for example, from therapy related nausea, vomiting, or diarrhea), or renal failure (for example, from therapy induced dehydration and pre-renal azotemia or directly toxic effects of chemotherapy).

Our analyses to explore the relation between index admission diagnoses and comorbidities as the causes of readmission further emphasized the importance of comorbidities. For example, when patients with a comorbidity of chronic heart failure had a 30 day potentially avoidable readmission due to an acute heart failure exacerbation, in half of the cases $(50 \%$; 27/54) the patients had a different primary diagnosis during the index admission (fig $2 \Downarrow$ ). Similarly, in cases of atrial fibrillation, ischemic heart disease, chronic kidney disease, and neoplasm, $55-80 \%$ of patients who were readmitted for an acute episode of their underlying chronic comorbidity had a different primary diagnosis at the index admission.

\section{Comorbidities and risk of potentially avoidable readmission}

Patients with cancer had an almost twofold increase in adjusted risk of potentially avoidable readmission in comparison with patients without cancer (table $4 \Downarrow$ ). However, when readmitted, patients with cancer had a similar adjusted risk of readmissions deemed potentially avoidable (versus unavoidable) to those without cancer (table $5 \Downarrow$ ). Patients discharged with a diagnosis of chronic heart failure had a significant $23 \%$ increased adjusted risk of having a potentially avoidable readmission (table $4 \Downarrow$ ). Readmissions among patients with chronic heart failure had a non-significant $9 \%$ higher adjusted risk of being potentially avoidable in comparison with patients without chronic heart failure (table $5 \Downarrow$ ). Patients with chronic kidney disease had not 
only a significantly higher risk of being deemed potentially avoidable readmission (table $4 \Downarrow$ ) but also a significantly higher proportion of readmissions deemed potentially avoidable than in those without the disease (table $5 \Downarrow$ ). For patients with the other comorbidities (diabetes mellitus, ischemic heart disease, atrial fibrillation, and chronic obstructive pulmonary disease), we found no statistically significant differences in adjusted risk of avoidable readmission or in the proportion of readmissions deemed potentially avoidable compared with patients without those diseases.

\section{Discussion}

In this medical cohort, we found that the five most frequent primary diagnoses of readmission were often related, either directly or indirectly, to patients' specific comorbidities. Also, although infection was the most frequent cause of potentially avoidable readmission overall, acute heart failure was the most frequent cause of potentially avoidable readmission among patients with five of the seven comorbidities we studied, especially the cardiovascular ones. In patients readmitted for a primary diagnosis that was related to a comorbidity (for example, acute heart failure exacerbation in a patient with chronic heart failure), the patients were more often than not discharged from the index hospital admission with a different primary diagnosis. These findings do not negate the role of the primary diagnosis of the index admission in transitional care, but they do underscore the importance of patients' underlying comorbidities in explaining the primary causes of 30 day potentially avoidable readmissions.

\section{Comparison with other studies}

The study is innovative, as it provides insight regarding readmission diagnoses in patients with each of the most frequent comorbidities, instead of restricting the analysis to the primary diagnosis of the index admission. It also differentiates unavoidable from potentially avoidable readmissions and gives adjusted measures of risk. It extends the findings of two major studies that looked at causes of readmission on the basis of the primary diagnosis of the index admission. ${ }^{12}$ These studies found that most of the causes of readmission were different from the specific first diagnosis of the index admission, suggesting the importance of underlying comorbidities. It is therefore interesting to see here that almost all of the top five primary diagnoses of potentially avoidable readmission found for each comorbidity are possible direct or indirect complications of that comorbidity. Besides the neoplasm example provided in the results section, in patients with chronic obstructive pulmonary disease, for example, infections, chronic obstructive pulmonary disease exacerbations, and (right) heart failure are direct complications, ${ }^{14-17}$ whereas neoplasm and venous thromboembolism may be explained by shared risk factors such as smoking. ${ }^{18-20}$

One appealing explanation for these results is that the acute condition responsible for the index admission weakens the overall health of the patient and induces a higher risk of complications or exacerbations related to the (previously) stable comorbidity. The post-discharge period is a fragile period, which has been referred to as "post-hospital syndrome.",21 This syndrome has been described as a period of vulnerability due to impaired physiological systems, depleted reserves, and lower body resistance against health threats, on top of the acute illness responsible for the index admission. Our study results bring another dimension to this theory: that comorbidities of patients also play a significant role in the post-discharge period. They might be well exacerbated by the acute illness and the stress of the index admission, and may consequently lead to new acute illnesses that increase the risk of readmission. In addition, changes made to chronic drug treatment in the hospital and after discharge may cause loss of disease control or adverse drug events, which represent a large proportion of all post-discharge adverse events. ${ }^{22}$ Lastly, diversion of attention from chronic comorbidities to the acute illness may also play a role, leading, for example, to insufficient monitoring after discharge.

As much of the existing literature on readmissions focuses on heart failure, it is worth noting that readmissions were most often due to infections in this study. This important finding should reinforce our efforts to better understand the processes that lead to readmissions for infectious diseases and how they can be monitored and prevented. This cause of readmission was not listed as a primary diagnosis of readmission in previous studies, as they looked at subcategories of infectious diseases such as pneumonia, urinary tract infection, and septicemia instead of considering them as one category. We chose to combine them, as the clinical actions to be taken (for example, post-discharge surveillance for signs or symptoms of worsening infection) are similar for all of them (as opposed to the various heart diseases, for which the potential actions to be taken are likely to be different).

The percentage of readmissions deemed potentially avoidable was similar to that found in a previous literature review. ${ }^{23} \mathrm{We}$ found three comorbidities associated with higher adjusted risk for potentially avoidable readmission: neoplasm, heart failure, and chronic renal failure. What all three have in common is a set of complications that lead to readmission and are somewhat predictable and amendable to monitoring, with the potential to take action before readmission is needed, at least in some patients. Patients with chronic kidney disease, when readmitted, were also more likely to have their readmissions deemed potentially avoidable. ${ }^{24}$

\section{Limitations of study}

This study has several limitations. Firstly, it is a single centre study in a tertiary care hospital. The case mix of patients discharged from the study hospital may differ from that of other hospitals, so the results may not be generalizable to other hospitals, especially to community hospitals, although it is likely similar to other academic medical centers in the United States and elsewhere. However, Brigham and Women's Hospital is associated with the Dana-Farber Cancer Institute, which might increase the number of complex cancer patients in our cohort (and therefore the risk of avoidable readmission in these patients). Regarding standards for transitional care at Brigham and Women's Hospital, preliminary results from a benchmarking study of 13 hospitals indicate that Brigham and Women's Hospital is similar to other hospitals in terms of degree of communication with primary care physicians, time to follow-up, and use of care coordination and may have better systems in place for discharge documentation. ${ }^{25}$

Secondly, we cannot prove that the estimated $20 \%$ of patients readmitted outside the Partners network have similar patterns of readmission. One might expect, for example, two opposing forces: patients might preferentially return to Brigham and Women's Hospital with a complication related to their primary diagnosis from the index admission but also be more likely to return to Brigham and Women's Hospital if they have a specialist there who cares for one of their comorbidities.

Thirdly, the differentiation between potentially avoidable and unavoidable readmissions cannot be perfect. A recent systematic 
review showed important variations in the definition of preventability among different studies and adjudicators. ${ }^{23}$ Nevertheless, although SQLape may have false negatives, mainly due to complications that are not coded in the readmission, it does have the advantages of using clear and clinically logical criteria, being very reproducible, and allowing for large data analysis. Other definitions of preventable readmissions (such as those of the US Agency for Healthcare Research and Quality, which uses ambulatory care sensitive conditions, or the US Centers for Medicare and Medicaid Services, which uses an algorithm to exclude planned readmissions) might produce different results, but no inherent reason exists to believe that these would be more valid than those presented here.

Fourthly, we were not able to adjust the analysis for functional status or other factors such as appropriateness of drugs, clinical stability at discharge, or social networks that might influence readmission. We cannot exclude the possibility of residual confounding in our models. The extent to which these would affect the causes of potentially avoidable readmission, as opposed to absolute risk of potentially avoidable readmission, is a matter of debate.

Fifthly, we were not able to assess the severity of each comorbidity. One may argue that the primary readmission diagnosis depends on the severity of each comorbidity.

Sixthly, although we have provided examples of how each primary diagnosis at readmission could be related to each chronic comorbidity, and although these relations are likely, some diagnoses may not in fact be related (for example, gastrointestinal diseases not caused by cancer chemotherapy in a patient with cancer).

Finally, owing to the many stratifications between each comorbidity and the readmission diagnoses, we may have had insufficient power to detect smaller differences in the preventability of readmissions by comorbidity.

\section{Implications}

This study has several implications. Transitions of care should focus not only on the acute condition responsible for the index admission but also on patients' underlying comorbidities that may increase the risk of new, acute complications. Interventions could include close follow-up and monitoring of patients' comorbidities in the post-discharge period. More attention could be paid in particular to patients with neoplasm, heart failure, and chronic renal failure who are at higher risk of potentially avoidable readmission than are patients without these conditions. Heart failure in particular should be a focus (for example, with close monitoring of weights and renal function) in patients who have the condition, regardless of the other heart conditions with which it frequently coexists. Lastly, further work is needed to explore the nature of infections causing potentially avoidable readmission and to identify possible ways in which they could be avoided in the future.

\section{Conclusions}

By providing a description of primary diagnoses and patterns of readmissions for patients with common comorbidities, our study supports the need for post-discharge care to focus attention not just on the primary index hospital admission diagnosis but also on the underlying comorbidities that may cause acute new complications that lead to readmission.

We thank Yves Eggli for having screened the database for potentially avoidable readmissions by using the algorithm SQLape.
Contributors: JD and JLS made substantial contributions to the study conception and design. All authors were involved in the analysis and interpretation of the data and in the drafting and final approval of the manuscript. JD is the guarantor.

Funding: JD was supported by the Swiss National Science Foundation and the Swiss Foundation for Medical-Biological Scholarships. The Swiss Science National Foundation and the Swiss Foundation for Medical-Biological Scholarships had no role in the design and conduct of this study, the analysis or interpretation of the data, or the preparation of this manuscript.

Competing interests: All authors have completed the ICMJE uniform disclosure form at www.icmje.org/coi_disclosure.pdf and declare: JD was supported by the Swiss National Science Foundation and the Swiss Foundation for Medical-Biological Scholarships; JLS is a consultant to QuantiaMD, for whom he has helped to create online educational materials for both providers and patients regarding patient safety, including drug safety, during transitions in care (the findings of this study are not a part of those materials); JLS has received grant funding from Sanofi Aventis for an investigator initiated study to design and evaluate an intensive discharge and follow-up intervention in patients with diabetes; no other relationships or activities that could appear to have influenced the submitted work.

Ethical approval: The study protocol was approved by the institutional review board of Brigham and Women's Hospital/Partners Healthcare (protocol 2010P001794).

Transparency: The lead author (the manuscript's guarantor) affirms that the manuscript is an honest, accurate, and transparent account of the study being reported; that no important aspects of the study have been omitted; and that any discrepancies from the study as planned (and, if relevant, registered) have been explained.

Data sharing: No additional data available.

1 Jencks SF, Williams MV, Coleman EA. Rehospitalizations among patients in the Medicare fee-for-service program. N Engl J Med 2009;360:1418-28.

2 Dharmarajan K, Hsieh AF, Lin Z, Bueno H, Ross JS, Horwitz LI, et al. Diagnoses and timing of 30-day readmissions after hospitalization for heart failure, acute myocardial infarction, or pneumonia. JAMA 2013;309:355-63.

3 Zekry D, Loures Valle BH, Graf C, Michel JP, Gold G, Krause KH, et al. Prospective comparison of 6 comorbidity indices as predictors of 1 -year post-hospital discharge institutionalization, readmission, and mortality in elderly individuals. J Am Med Dir Assoc 2012;13:272-8.

4 Van WC, Dhalla IA, Bell C, Etchells E, Stiell IG, Zarnke K, et al. Derivation and validation of an index to predict early death or unplanned readmission after discharge from hospital to the community. CMAJ 2010;182:551-7.

5 Librero J, Peiro S, Ordinana R. Chronic comorbidity and outcomes of hospital care: length of stay, mortality, and readmission at 30 and 365 days. J Clin Epidemiol 1999;52:171-9.

6 Jasti H, Mortensen EM, Obrosky DS, Kapoor WN, Fine MJ. Causes and risk factors for rehospitalization of patients hospitalized with community-acquired pneumonia. Clin Infect Dis 2008;46:550-6.

7 Schnipper JL, Roumie CL, Cawthon C, Businger A, Dalal AK, Mugalla I, et al. Rationale and design of the Pharmacist Intervention for Low Literacy in Cardiovascular Disease (PILL-CVD) study. Circ Cardiovasc Qual Outcomes 2010;3:212-9.

8 Kripalani S, Roumie CL, Dalal AK, Cawthon C, Businger A, Eden SK, et al. Effect of a pharmacist intervention on clinically important medication errors after hospital discharge: a randomized trial. Ann Intern Med 2012;157:1-10.

9 Halfon $\mathrm{P}$, Eggli $\mathrm{Y}$, van MG, Chevalier J, Wasserfallen JB, Burnand B. Measuring potentially avoidable hospital readmissions. $J$ Clin Epidemiol 2002:55:573-87.

10 SQlape. Potentially avoidable readmissions. 2013. www.sqlape.com/Readmissions-e. $\mathrm{htm}$.

11 Halfon P, Eggli Y, Pretre-Rohrbach I, Meylan D, Marazzi A, Burnand B. Validation of the potentially avoidable hospital readmission rate as a routine indicator of the quality of hospital care. Med Care 2006;44:972-81.

12 Donze J, Aujesky D, Williams D, Schnipper JL. Potentially avoidable 30-day hospital readmissions in medical patients: derivation and validation of a prediction model. JAMA Intern Med 2013;173:632-8.

13 Zeger SL, Liang KY. Longitudinal data analysis for discrete and continuous outcomes. Biometrics 1986;42:121-30.

14 Wells JM, Washko GR, Han MK, Abbas N, Nath H, Mamary AJ, et al. Pulmonary arterial enlargement and acute exacerbations of COPD. N Engl J Med 2012;367:913-21.

15 Zvezdin B, Milutinov S, Kojicic M, Hadnadjev M, Hromis S, Markovic M, et al. A postmortem analysis of major causes of early death in patients hospitalized with COPD exacerbation. Chest 2009;136:376-80.

16 Naeije R. Pulmonary hypertension and right heart failure in chronic obstructive pulmonary disease. Proc Am Thorac Soc 2005;2:20-2.

17 Sethi S, Murphy TF. Infection in the pathogenesis and course of chronic obstructive pulmonary disease. N Engl J Med 2008;359:2355-65.

18 Shetty R, Seddighzadeh A, Piazza G, Goldhaber SZ. Chronic obstructive pulmonary disease and deep vein thrombosis: a prevalent combination. $J$ Thromb Thrombolysis 2008;26:35-40. 


\section{What is already known on this topic}

Evidence shows that readmission diagnoses usually differ from the specific acute diagnosis responsible for the index hospital admission Higher comorbidity has been shown to be associated with an increased risk of readmission, but little is known about the effect of the most common specific comorbidities on the causes of readmissions

Although the causes of readmission in general have been identified, few data are available regarding to what extent the causes of all readmissions differ from the causes of avoidable ones

\section{What this study adds}

In patients with common comorbidities, the five most common primary diagnoses of potentially avoidable readmissions were possible complications of each underlying comorbidity

In many cases, these principal diagnoses were unrelated to those of the index admission

Post-discharge care should focus attention not just on the cause of the index admission but also on the comorbidities patients have

19 Gunen H, Gulbas G, In E, Yetkin O, Hacievliyagil SS. Venous thromboemboli and exacerbations of COPD. Eur Respir J 2010;35:1243-8.

20 Maldonado F, Bartholmai BJ, Swensen SJ, Midthun DE, Decker PA, Jett JR. Are airflow obstruction and radiographic evidence of emphysema risk factors for lung cancer? A nested case-control study using quantitative emphysema analysis. Chest 2010;138:1295-302.

21 Krumholz HM. Post-hospital syndrome-an acquired, transient condition of generalized risk. N Engl J Med 2013;368:100-2.

22 Forster AJ, Murff HJ, Peterson JF, Gandhi TK, Bates DW. The incidence and severity of adverse events affecting patients after discharge from the hospital. Ann Intern Med 2003;138:161-7.

23 Van Walraven C, Bennett C, Jennings A, Austin PC, Forster AJ. Proportion of hospita readmissions deemed avoidable: a systematic review. CMAJ 2011;183:E391-402.

24 Chu LW, Pei CK. Risk factors for early emergency hospital readmission in elderly medical patients. Gerontology 1999;45:220-6.
25 Auerbach A, Lindenauer PK, Metlay J, Robinson E, Patel M, Williams M, et al. The Hospital Medicine Reengineering Network (HOMERuN): a learning network focused on hospital care. Acad Med [forthcoming].

\section{Accepted: 15 November 2013}

\section{Cite this as: BMJ 2013;347:f7171}

This is an Open Access article distributed in accordance with the Creative Commons Attribution Non Commercial (CC BY-NC 3.0) license, which permits others to distribute, remix, adapt, build upon this work non-commercially, and license their derivative works on different terms, provided the original work is properly cited and the use is non-commercial. See: http://creativecommons.org/licenses/by-nc/3.0/. 


\section{Tables}

\begin{tabular}{|c|c|c|c|c|}
\hline \multicolumn{5}{|l|}{ Table 1| Baseline characteristics } \\
\hline Characteristic & Entire cohort $(n=10731)$ & All readmissions $(n=2398)$ & $\begin{array}{l}\text { Potentially avoidable } \\
\text { readmissions }(n=858)\end{array}$ & $\begin{array}{l}\text { Unavoidable readmissions } \\
\qquad(n=1540)\end{array}$ \\
\hline Mean (SD) age, years & $61.0(16.7)$ & $59.7(16.4)$ & $60.7(16.4)$ & $59.2(16.4)$ \\
\hline No (\%) male sex & $5265(49.1)$ & $1208(50.4)$ & $409(47.7)$ & 799 (51.9) \\
\hline \multicolumn{5}{|l|}{ Ethnicity—No (\%): } \\
\hline Non-Hispanic white & $7821(72.9)$ & $1814(75.7)$ & $630(73.4)$ & $1184(76.9)$ \\
\hline Non-Hispanic black & $1729(16.1)$ & $369(15.4)$ & $136(15.9)$ & $233(15.1)$ \\
\hline Hispanic & $868(8.1)$ & $173(7.2)$ & $77(9.0)$ & $96(6.2)$ \\
\hline Other & $313(2.9)$ & $42(1.8)$ & $15(1.8)$ & $27(1.8)$ \\
\hline \multicolumn{5}{|l|}{ Language-No (\%): } \\
\hline English & $9790(91.2)$ & $2221(92.6)$ & $787(91.7)$ & $1434(93.1)$ \\
\hline Spanish & $534(5.0)$ & $102(4.3)$ & $49(5.7)$ & $53(3.4)$ \\
\hline Other & $407(3.8)$ & $75(3.1)$ & $22(2.6)$ & $53(3.4)$ \\
\hline \multicolumn{5}{|l|}{ Marital status-No (\%): } \\
\hline Currently married or partner & $5504(51.3)$ & $1258(52.5)$ & $440(51.3)$ & $818(53.1)$ \\
\hline Single/never married & $2714(25.3)$ & $621(25.9)$ & $216(25.2)$ & $405(26.3)$ \\
\hline Separated/divorced/ widowed/no answer & $2513(23.4)$ & $519(21.6)$ & $202(23.5)$ & $317(20.6)$ \\
\hline \multicolumn{5}{|l|}{ Primary insurance-No (\%): } \\
\hline Medicare & $5374(50.1)$ & $1135(47.3)$ & $430(50.1)$ & $705(45.8)$ \\
\hline Medicaid & $885(8.3)$ & $215(9.0)$ & $77(9.0)$ & $138(9.0)$ \\
\hline Private & $4453(41.5)$ & $1038(43.3)$ & $348(40.6)$ & $690(44.8)$ \\
\hline No insurance & $19(0.2)$ & $10(0.4)$ & $3(0.4)$ & $7(0.5)$ \\
\hline \multicolumn{5}{|l|}{ Type of index admission—No (\%): } \\
\hline Elective & $1502(14.0)$ & $401(16.7)$ & $80(9.3)$ & $321(20.8)$ \\
\hline Urgent or emergent & $9229(86.0)$ & $1997(83.3)$ & $778(90.7)$ & $1219(79.2)$ \\
\hline $\begin{array}{l}\text { Median (IRQ) length of stay of index } \\
\text { admission, days }\end{array}$ & $4(3-7)$ & $5(3-8)$ & $5(3-8)$ & $4.5(3-8)$ \\
\hline $\begin{array}{l}\text { Median (IRQ) No of hospital admissions in } \\
\text { previous year }\end{array}$ & $1(0-2)$ & $1(0-3)$ & $1(0-3)$ & $1(0-3)$ \\
\hline Mean (SD) No of selected chronic diseases & $1.74(1.22)$ & $1.89(1.17)$ & $2.05(1.25)$ & $1.80(1.11)$ \\
\hline \multicolumn{5}{|l|}{ Selected comorbidities-No (\%): } \\
\hline Neoplasm & $4129(38.5)$ & $1341(55.9)$ & $441(51.4)$ & $900(58.4)$ \\
\hline Diabetes mellitus & $2639(24.6)$ & $569(23.7)$ & $238(27.7)$ & $331(21.5)$ \\
\hline Chronic heart failure & $2308(21.5)$ & $488(20.4)$ & $209(24.4)$ & $279(18.1)$ \\
\hline Ischemic heart disease & $2823(26.3)$ & $537(22.4)$ & $211(24.6)$ & $326(21.2)$ \\
\hline Atrial fibrillation & $1832(17.1)$ & $334(13.9)$ & $134(15.6)$ & $200(13.0)$ \\
\hline Chronic obstructive pulmonary disease & $1078(10.0)$ & $231(9.6)$ & $87(10.1)$ & $144(9.4)$ \\
\hline Chronic kidney disease & $1776(16.6)$ & $410(17.1)$ & $184(21.5)$ & $226(14.7)$ \\
\hline
\end{tabular}




\begin{tabular}{|c|c|c|c|c|c|}
\hline \multirow[b]{2}{*}{ Comorbidity } & \multicolumn{5}{|c|}{ Five most likely primary readmission diagnoses } \\
\hline & First & Second & Third & Fourth & Fifth \\
\hline Neoplasm $(n=1341)$ & $\begin{array}{l}\text { Neoplasm (29.6\%; } \\
\quad n=397)\end{array}$ & Infection (11.1\%; $n=149)$ & $\begin{array}{l}\text { Gastrointestinal disorder } \\
\qquad(3.1 \% ; n=41)\end{array}$ & $\begin{array}{l}\text { Liver disorder }(2.3 \% \text {; } \\
\qquad \mathrm{n}=31)\end{array}$ & $\begin{array}{l}\text { Metabolic disorder }(2.1 \% ; \\
n=28)\end{array}$ \\
\hline $\begin{array}{l}\text { Diabetes mellitus } \\
(n=563)\end{array}$ & Infection $(10.7 \% ; n=60)$ & $\begin{array}{l}\text { Heart failure }(10.3 \% ; \\
n=58)\end{array}$ & Neoplasm (8.2\%; n=46) & $\begin{array}{l}\text { Liver disorder }(5.0 \% \text {; } \\
\qquad \mathrm{n}=28)\end{array}$ & $\begin{array}{c}\text { Gastrointestinal disorder } \\
(4.4 \% ; n=25)\end{array}$ \\
\hline $\begin{array}{l}\text { Chronic heart failure } \\
(\mathrm{n}=483)\end{array}$ & $\begin{array}{l}\text { Heart failure (21.5\%; } \\
\qquad n=104)\end{array}$ & Infection (10.1\%; n=49) & $\begin{array}{l}\text { Ischemic heart disease } \\
(5.8 \% ; n=28)\end{array}$ & Neoplasm (4.6\%; n=22) & Arrhythmia $(3.3 \% ; n=16)$ \\
\hline $\begin{array}{l}\text { Ischemic heart disease } \\
(n=533)\end{array}$ & Infection $(10.9 \% ; n=58)$ & $\begin{array}{l}\text { Heart failure }(10.5 \% ; \\
n=56)\end{array}$ & $\begin{array}{l}\text { Ischemic heart disease } \\
\qquad(8.3 \% ; n=44)\end{array}$ & Neoplasm (6.9\%; n=37) & $\begin{array}{c}\text { Gastrointestinal disorder } \\
(3.8 \% ; n=20)\end{array}$ \\
\hline Atrial fibrillation $(\mathrm{n}=332)$ & $\begin{array}{l}\text { Heart failure (13.9\%; } \\
\qquad \mathrm{n}=46)\end{array}$ & Infection (12.7\%; $\mathrm{n}=42)$ & $\begin{array}{l}\text { Ischemic heart disease } \\
\qquad(6.9 \% ; n=23)\end{array}$ & Arrhythmia $(6.6 \% ; n=22)$ & Neoplasm $(5.1 \% ; n=17)$ \\
\hline COPD $(n=229)$ & Infection (13.1\%; $\mathrm{n}=30)$ & Neoplasm (12.7\%; n=29) & Heart failure $(11.4 \% ; n=26)$ & COPD $(7.0 \% ; n=16)$ & Arrhythmia $(3.9 \% ; n=9)$ \\
\hline $\begin{array}{l}\text { Chronic kidney disease } \\
(\mathrm{n}=408)\end{array}$ & $\begin{array}{l}\text { Heart failure }(15.2 \% \text {; } \\
\qquad n=62)\end{array}$ & Infection (8.8\%; n=36) & Renal failure (5.4\%; n=22) & $\begin{array}{l}\text { Ischemic heart disease } \\
\qquad(4.4 \% ; \mathrm{n}=18)\end{array}$ & $\begin{array}{c}\text { Gastrointestinal disorder } \\
(4.4 \% ; n=18)\end{array}$ \\
\hline Entire cohort $(\mathrm{n}=2387)$ & $\begin{array}{l}\text { Neoplasm (16.8\%; } \\
n=402)\end{array}$ & Infection (10.9\%; n=260) & Heart failure $(4.9 \% ; n=116)$ & $\begin{array}{l}\text { Liver disorder }(4.4 \% ; \\
\qquad n=105)\end{array}$ & $\begin{array}{c}\text { Gastrointestinal disorder } \\
\qquad(3.6 \% ; n=86)\end{array}$ \\
\hline
\end{tabular}




\begin{tabular}{|c|c|c|c|c|c|}
\hline \multirow[b]{2}{*}{ Comorbidity } & \multicolumn{5}{|c|}{ Five most likely primary readmission diagnoses } \\
\hline & First & Second & Third & Fourth & Fifth \\
\hline Neoplasm $(n=441)$ & Neoplasm (16.3\%; n=72) & Infection (12.9\%; n=57) & $\begin{array}{l}\text { Metabolic disorder (4.3\%; } \\
\qquad \mathrm{n}=19)\end{array}$ & $\begin{array}{c}\text { Gastrointestinal disorder } \\
(3.9 \% ; n=17)\end{array}$ & Renal failure $(2.7 \% ; n=12)$ \\
\hline $\begin{array}{l}\text { Diabetes mellitus } \\
(\mathrm{n}=236)\end{array}$ & $\begin{array}{l}\text { Heart failure }(12.7 \% ; \\
n=30)\end{array}$ & Infection $(8.9 \% ; n=21)$ & Neoplasm (6.4\%; n=15) & $\begin{array}{l}\text { Ischemic heart disease } \\
\qquad(4.7 \% ; n=11)\end{array}$ & Liver disorder $4.2 \% ; n=10$ ) \\
\hline $\begin{array}{l}\text { Chronic heart failure } \\
(n=207)\end{array}$ & $\begin{array}{l}\text { Heart failure }(26.1 \% \text {; } \\
\qquad n=54)\end{array}$ & Infection (8.2\%; n=17) & $\begin{array}{l}\text { Ischemic heart disease } \\
\qquad(7.7 \% ; n=16)\end{array}$ & Arrhythmia $(2.9 \% ; n=6)$ & Renal failure $(2.9 \% ; n=6)$ \\
\hline $\begin{array}{l}\text { Ischemic heart disease } \\
(\mathrm{n}=208)\end{array}$ & $\begin{array}{l}\text { Heart failure (13.5\%; } \\
\qquad \mathrm{n}=28)\end{array}$ & Infection (11.5\%; $\mathrm{n}=24)$ & $\begin{array}{l}\text { Ischemic heart disease } \\
\qquad(9.6 \% ; n=20)\end{array}$ & Arrhythmia $(4.8 \% ; n=10)$ & Renal failure $(3.4 \% ; n=7)$ \\
\hline Atrial fibrillation $(n=132)$ & $\begin{array}{l}\text { Heart failure (18.2\%; } \\
\qquad \mathrm{n}=24)\end{array}$ & Infection $(11.4 \% ; n=15)$ & $\begin{array}{l}\text { Ischemic heart disease } \\
\qquad(8.3 \% ; n=11)\end{array}$ & Arrhythmia $(8.3 \% ; n=11)$ & $\begin{array}{c}\text { Gastrointestinal disorder } \\
(3.8 \% ; n=5) \\
\end{array}$ \\
\hline $\operatorname{COPD}(n=86)$ & Infection $(16.3 \% ; n=14)$ & $\begin{array}{l}\text { Heart failure (16.3\%; } \\
\qquad n=14)\end{array}$ & Neoplasm $(9.3 \% ; n=8)$ & COPD $(5.8 \% ; n=5)$ & $\begin{array}{c}\text { Venous thromboembolism } \\
(3.5 \% ; n=3)\end{array}$ \\
\hline $\begin{array}{l}\text { Chronic kidney disease } \\
(\mathrm{n}=184)\end{array}$ & $\begin{array}{l}\text { Heart failure }(20.7 \% \text {; } \\
\qquad n=38)\end{array}$ & Infection $(8.2 \% ; n=15)$ & Renal failure (7.1\%; $n=13)$ & $\begin{array}{l}\text { Ischemic heart disease } \\
\qquad(6.0 \% ; \mathrm{n}=11)\end{array}$ & Liver disorder $(2.7 \% ; n=5)$ \\
\hline Entire cohort $(\mathrm{n}=854)$ & Infection $(11.6 \% ; n=99)$ & Neoplasm $(8.4 \% ; n=72)$ & Heart failure $(7.1 \% ; n=61)$ & $\begin{array}{l}\text { Gastrointestinal disorder } \\
\qquad(4.7 \% ; n=40)\end{array}$ & Liver disorder $(3.9 \% ; n=33)$ \\
\hline
\end{tabular}


Table 4| Relative risk of having 30 day potentially avoidable readmission versus no readmission for each comorbidity $(\mathbf{n}=9191)$

\begin{tabular}{lcc} 
Comorbidity & Crude relative risk $(95 \% \mathrm{Cl})$ & Adjusted relative risk $\mathbf{~}^{*}\left(\mathbf{9 5} \% \mathrm{Cl}^{)}\right.$ \\
Neoplasm & $1.37(1.26$ to 1.49$)$ & $1.83(1.55$ to 2.15$)$ \\
\hline Diabetes mellitus & $1.04(0.99$ to 1.09$)$ & $1.16(0.99$ to 1.38$)$ \\
\hline Chronic heart failure & $1.03(0.99$ to 1.08$)$ & $1.23(1.02$ to 1.48$)$ \\
\hline Ischemic heart disease & $0.96(0.92$ to 1.00$)$ & $0.97(0.81$ to 1.17$)$ \\
\hline Atrial fibrillation & $0.97(0.94$ to 1.00$)$ & $0.95(0.77$ to 1.17$)$ \\
\hline Chronic obstructive pulmonary disease & $0.99(0.98$ to 1.02$)$ & $1.00(0.80$ to 1.27$)$ \\
\hline Chronic kidney disease & $1.06(1.03$ to 1.10$)$ & $1.26(1.04$ to 1.52$)$
\end{tabular}

*From single logistic regression model with all comorbidities, adjusted for length of stay of index hospital admission, mode of admission (elective or not), number of admissions in previous 12 months, number of procedures during index admission, and hemoglobin and sodium concentrations at discharge of index admission. 
Table 5| Relative risk of having avoidable versus unavoidable 30 day readmission for each comorbidity ( $\mathrm{n}=2398$ )

\begin{tabular}{lcc} 
Comorbidity & Crude relative risk (95\% Cl) & Adjusted relative risk $\mathbf{~}^{*}(\mathbf{9 5} \% \mathbf{C I})$ \\
\hline Neoplasm & $0.88(0.80$ to 0.96$)$ & $0.97(0.83$ to 1.13$)$ \\
\hline Diabetes mellitus & $1.29(1.09$ to 1.52$)$ & $1.13(0.98$ to 1.30$)$ \\
\hline Chronic heart failure & $1.34(1.12$ to 1.62$)$ & $1.09(0.92$ to 1.29$)$ \\
\hline Ischemic heart disease & $1.16(0.98$ to 1.38$)$ & $0.99(0.84$ to 1.16$)$ \\
\hline Atrial fibrillation & $1.20(0.95$ to 1.52$)$ & $1.03(0.86$ to 1.25$)$ \\
\hline Chronic obstructive pulmonary disease & $1.08(0.83$ to 1.42$)$ & $1.02(0.83$ to 1.24$)$ \\
\hline Chronic kidney disease & $1.46(1.19$ to 1.79$)$ & $1.18(1.00$ to 1.40$)$
\end{tabular}

*From single logistic regression model with all comorbidities, adjusted for length of stay of index hospital admission, mode of admission (elective or not), number of admissions in previous 12 months, number of procedures during index admission, and hemoglobin and sodium concentrations at discharge of index admission. 


\section{Figures}

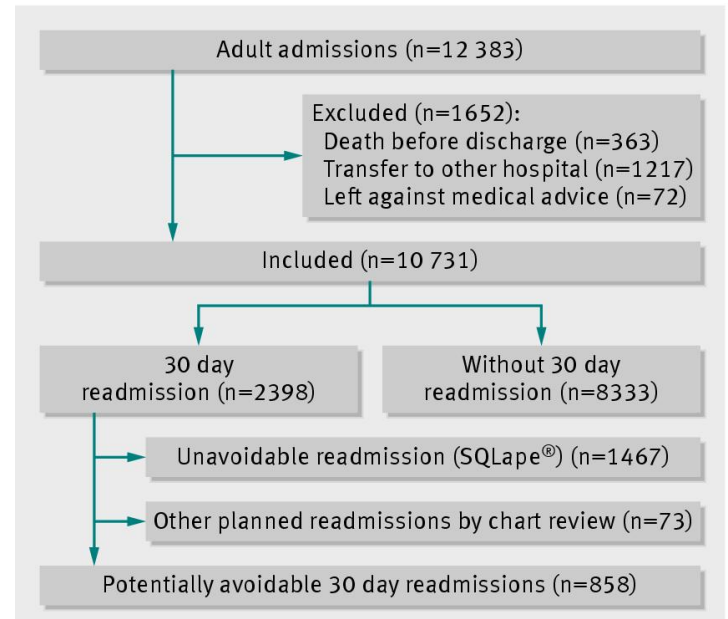

Fig 1 Flow chart of study

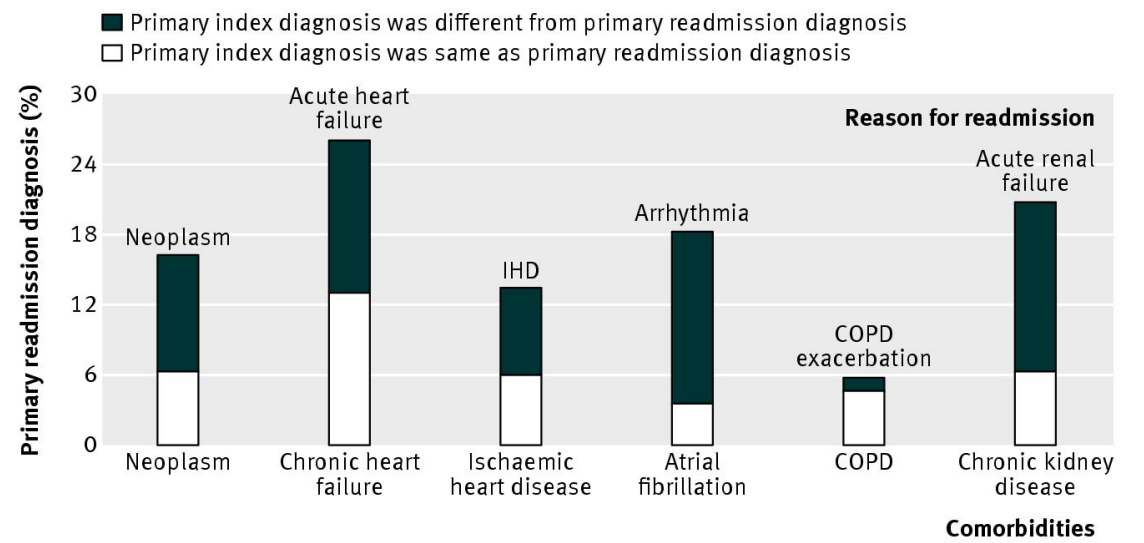

Fig 2 Match between primary diagnosis of index admission and 30 day potentially avoidable readmission among patients readmitted for acute exacerbation of their comorbidity. Diabetes mellitus is not shown because MS-DRG codes do not capture hyperglycemia specifically 